\title{
Fierce debate at Harvard
}

\section{Boston}

AT a faculty meeting said to have been the best-attended and most tumultuous in recent memory, some 300 members of the Harvard Medical School last week debated a proposal for new conflict-of-interest rules that would bar clinical researchers from financial ties with companies that could benefit from their research.

The proposed new rules were developed over the past year by a blue-ribbon committee appointed by Daniel C. Tosteson, dean of the medical school. The panel was set up shortly after a widely publicized case in which a former Harvard researcher was alleged to have failed to disclose properly a financial interest in a drug he was testing (see Nature 335, 754; 1988).

The proposed new rules would forbid any Harvard faculty member involved in human studies from acting as a paid consultant to any company with a financial stake in his or her research, and would forbid clinical researchers from owning stock in such companies. Non-clinical researchers would be required to disclose potential financial conflicts but would be allowed to retain financial equity in companies that sponsor their research provided that the sponsored-research was funded through university channels.

Although the proposed rules remain several steps away from adoption, they have sparked vociferous debate among Harvard Medical School faculty, who form a disparate group of researchers working in a variety of capacities at the school and at more than a dozen affiliated hospitals.

Barbara J. McNeil, head of the school's department of health care policy and chair of the committee that developed the rules, says that her panel stands firmly behind the proposal. "The committee believes quite strongly that we have produced a good document, and one that reflects a changing relationship between industry and university researchers", she says. The proposed rules address "increasing interest" on the part of the public "to know what we [researchers] are doing", McNeil says, while mandating only what she terms "parsimonious, relevant disclosure".

Other researchers however, claim that the guidelines "throw the baby out with the bathwater" and, if adopted, will make many researchers leave Harvard for more lenient institutions.

Opposition to the new rules is particularly strong and vocal at the Harvardaffiliated Massachusetts General Hospital.

Participants on both sides claim that despite an outcry from the biomedical community that forced the National Institutes of Health to back down temporarily from new stringent conflict-ofinterest rules (see Nature 343, 104; 11 January 1990), a change at Harvard is likely before long. At the minimum, guidelines for disclosure of researchers' financial ties are likely to be strengthened.

How stringent the new rules will ultimately be, however, remains uncertain. As John T. Potts, chair of general medical services at Massachusetts General Hospital explains, "Some people are belligerently entrepreneurial, and that won't do. Others find dealing with industry dirty, a position that would be disastrous for science and for our society. The trick is to get it right in the middle."

Seth Shulman
Tiger Team lands at Livermore

\section{San Francisco}

As part of efforts by the US Department of Energy (DoE) to restore confidence in environmental protection at its production, research and testing facilities, members of the agency's renowned 'Tiger Team' descended on Lawrence Livermore National Laboratory last week to assess the status of more than 30 separate facilities - including Site 300, where conventional explosives used to trigger nuclear warheads are tested.

About 50 Tiger Team members will take part in the four-to-six-week investigation, reporting on compliance with a host of federal, state and local regulations. The sprawling laboratory complex has close to 500 separate facilities. But to make its task manageable, the Tiger Team is concentrating on sections designated as either high or moderate hazard, including areas housing plutonium, tritium, or heavy elements.

In announcing the review, Tiger Team leader Ed Cumesty said the action is part of Energy Secretary James Watkins' efforts "to restore credibility to the department".

In a separate move, laboratory officials announced that pending $\mathrm{DoE}$ approval they were dropping plans to build a giant incinerator to burn several thousand tons of radioactive and toxic waste produced annually at the site. The incinerator formed a key part of a proposed $\$ 45$ million waste treatment facility. Instead, the laboratory is to focus resources on other means of waste disposal and decontamination.

Local environmental groups praise both the incinerator decision and the Tiger Team review but have repeated their demand for an independent oversight body at the laboratory. Widespread ground-water contamination has been discovered in the area and the laboratory is designated a Superfund site by the Environmental protection Agency. Laboratory officials say most of the contamination comes from aeroplane engine cleaning operations conducted during the Second World War.

Investigations at six other $\mathrm{DoE}$ facilities have revealed several weak points including shortages of qualified staff, undisciplined management systems and ill-defined authority and responsibility for dealing with environmental health and safety regulations.

DoE is now trying to improve its performance. A spokesman said that $\$ 2.300$ million has been appropriated in the current fiscal year to help the agency deal with environmental restoration and waste management. The proposed 1991 budget boosts this to $\$ 2.700$ million.

A draft report of the Lawrence Livermore National Laboratory findings will be prepared in early April. Other Tiger Team reviews are scheduled for the Sandia National Laboratories and the Brookhaven National Laboratory.

Robert Buderi 